\title{
Critical Issues in Interaction Design
}

\author{
Mark Blythe \\ University of York \\ Department of Computer Science \\ York, UK
}

mblythe@cs.york.ac.uk

\author{
Jeffrey Bardzell \& Shaowen \\ Bardzell \\ Indiana University \\ School of Informatics \\ Bloomington IN 47406 \\ jbardzel@indiana.edu \\ selu@indiana.edu
}

\author{
Alan Blackwell \\ University of Cambridge \\ Computer Laboratory \\ William Gates Building \\ Cambridge, UK
}

\section{Alan.Blackwell@cl.cam.ac.uk}

\begin{abstract}
Computing technology is now so entwined with everyday life that enquiries into human computer interaction (HCI) are also studies of society and culture Cultural and Critical theory is then increasingly relevant to studies of Human Computer Interaction (HCI). It is both timely and important to develop understandings of the strengths and limitations of the various perspectives available within the fractious traditions of cultural and critical theory. This workshop will consider the challenges of making such theory relevant and accessible to HCI and interaction design.
\end{abstract}

\section{Categories and Subject Descriptors}

H5. Information interfaces and presentation H 5.2 User Interfaces. Theory and Methods

\section{General Terms}

Design, Human Factors, Theory

\section{Keywords}

User experience, Evaluation, Interpretation, Methods, Critical theory, Design

\section{INTRODUCTION}

Computing technology is now so pervasive that the study of Human Computer Interaction (HCI) is almost the study of everyday life. The expansion of contexts for HCI is vast and change has been rapid, at least in rich nations. It is now generally agreed that the historical concerns of the field such as usability and efficiency are no longer sufficient scopes of inquiry. There have been turns to fun and enjoyment (e.g., 14, 8) emotional design (e.g. 17) experience design (e.g., 16), culturally situated design (e.g., 15) critical and reflective design (e.g. 1, 13) beauty and aesthetics (e.g., 15) and technology for social action (e.g., 11).

As HCI has become more implicated in culture, the field has become concerned with critical theory (e.g., 4, 6, 10). Critical theory is a catch-all term that encompasses a number of writers and disciplines; it includes the sub fields of hermeneutics, phenomenology, semiotics, marxism, feminism, deconstruction, and postmodernism, among others. Critical theory has

\section{(c) The Author 2008.}

Published by the British Computer Society traditionally aimed to help critics, understand, explicate, and evaluate dense cultural phenomena, such as literature, film, social ritual, and mass media.

HCI has always been something of a magpie discipline, picking useful methods from fields such as cognitive psychology, sociology and engineering. Most user research throughout the various waves of HCI has been broadly empirical, even if ostensibly derived from different disciplines. As we enter an age of social, cultural and political computing, the goals of the field have expanded to include categories that require new methods and analytical procedures. While semiotics and phenomenology have received much attention in HCI other perspectives from critical theory have been neglected and may be equally valuable.

\section{BACKGROUND}

Disciplines that have long histories of scholarship in the relationships between culture, cognition, media, and social change may be able to inform HCI's new problem spaces. Although HCI has a history of inter-disciplinary collaboration, the language of critical theory is very different to that of previous partner disciplines such as cognitive psychology. As Don Norman notes:

"I find that the style of thinking and writing from within Cognitive Science (which is where I reside) is so different from many of the European semioticians that although I think I am in agreement with much of what they are saying I can't understand them well enough to make any solid connection. We inhabit different cultures" (7).

Connections are already becoming firmer. Paul Dourish, for example, provided an introduction to phenomenology for HCI (12). McCarthy and Wright provided an overview of pragmatism and Bakhtinian literary theory (16). Semiotics, too, has entered HCI (e.g., 10, 2, 6), though its use is often oriented toward engineering goals, such as specifications of needs and requirements, rather than criticism, interpretation, or judgment (but see 3). While the exploration of particular perspectives from critical theory is valuable it is also important to understand the larger contexts and debates from which they emerged.

While the use of semiotics in HCI may be relatively new, it was all but abandoned in the 1970s in the humanities and replaced by theories that emphasized the constructed, rather than discovered, nature of meaning. These ideas were developed in critical traditions such as poststructuralism and reader-response theory. Their central tenet - that meaning is constructed through a "performance" of the text - has obvious applicability to $\mathrm{HCI}$, where the significance and experience of interactions is 
much more than an unlocking of meanings "hidden" in interfaces.

As HCI begins to appropriate concepts and strategies from critical theory, it risks repeating the mistakes of the past and reinventing concepts and interpretative strategies developed decades ago in other disciplines. Equally dangerous, lacking an understanding of the discourses from which these concepts arose, HCI practitioners run the risk of dilution and misappropriation, as complex concepts are taken from their theoretical backdrops and forced to work in service of other approaches without reflection on the significance of the transfer.

\section{ONWARD EVER ONWARD}

While theoretical orientations from social and cultural theory have been useful in HCI their adoption has often been piecemeal and a result of a particular practitioners' academic background. Critical theory offers a wide range of approaches to the analysis of cultural artifacts, some perspectives such as reception theory have made only rare appearances in the HCI literature (e.g. 9) others have not been used at all. These others may be equally if not more valuable, in particular poststructuralist and reader-oriented theories. Developing connections between critical theory and HCI is a major undertaking. The goal cannot be achieved in a paper by a handful of authors; it is a challenge and agenda for the field of HCI and will likely require much work. This workshop is designed to bring together some of the people who are interested in doing it.

\subsection{Plan and Goals of the Workshop}

The goals of the workshop are to:

- Provide a forum to discuss current interest in critical theory

- Identify the perspectives which are currently being used in HCI and those which are neglected

- Discuss the ways in which critical theory can be made relevant to design

- Consider problems of legitimating critical theory as a relevant source for $\mathrm{HCI}$

- Outline a research agenda

\section{REFERENCES}

1. Agre P. Toward a Critical Technical Practice: Lessons Learned in Trying to Reform AI in Geoffrey C. Bowker, Susan Leigh Star, William Turner, and Les Gasser, eds, Social Science, Technical Systems and Cooperative Work: Beyond the Great Divide, Erlbaum, 1997

2. Andersen, P. B. (2001). What semiotics can and cannot do for HCI. Knowledge-Based Systems, 14, 419-424.

3. Bardzell J., Creativity in Amateur Multimedia: Popular Culture, Critical Theory and HCI in Blythe M., Light A., O’Neil S., (Eds) Special Issue of
Human Technology on Culture, Creativity and Technology. Human Technology volume 3, Number 1 February 2007

4. Bardzell, J., \& Bardzell, S. (2008). Interaction Criticism: A Proposal and Framework for a New Discipline of HCI. CHI'08: CHI 2008 Extended Abstracts on Human Factors in Computing Systems. ACM: New York.

5. Bell, G., Blythe, M., Gaver, W., Sengers P., Wright P.(2003): Designing Culturally Situated Products for the Home: CHI 2003 New Horizons. Extended Abstracts pp1062-1063

6. Bertelsen, O. \& Pold, S. (2004) Criticism as an Approach to Interface Aesthetics. Nordichi 04 October 23-27 pp 23-32

7. Blythe M., \& Hassenzahl M., (2004) Interview with Don Norman. Special Issue of Interactions Magazine Volume 11, Issue 5 (September + October 2004) pp 43-36

8. Blythe, M.A., Overbeeke, K., Monk, A.F. and Wright, P.C. (2003) Funology: from usability to enjoyment. Kluwer Academic Publishers. Dordrecht, Boston, London

9. Davis M. (2003) Theoretical Foundations for Experiential Systems Design. ETP 032003 Berkeley, USA ACM 45-5

10. De Souza C. (2005) The Semiotic Engineering of Human-Computer Interaction. The MIT Press. Cambridge, Mass. London, England

11. Dearden A., \& Walker S. (2005) (Eds) Special Issue of Interacting with Computers: Designing For Civil Society - volume 17 (1),

12. Dourish P. (2001) Where The Action Is: The Foundations of Embodied Interaction. Cambridge MIT Press

13. Dourish P., Finlay J., Sengers P., and Wright P. "Reflective HCI: Towards a Critical Technical Practice.” Extended Abstract. CHI'04, April 2004.

14. Gaver, W. 2001. Designing for Ludic Aspects of Everyday Life. ERCIM News No. 47,

15. Hassenzahl, Marc (2004): The Interplay of Beauty, Goodness, and Usability in Interactive Products. In Human-Computer Interaction, 19 (4) pp. 319-349

16. McCarthy, J.C. \& Wright, P.C. (2004) Technology as Experience. The MIT Press. Cambridge, Mass. London, England

17. Norman, D.A., 2004, Emotional Design: Why We Love (or Hate) Everyday Things. (New York: Basic Books).

18. Sengers P., Boehner K., David S \& Kaye J. (2005) Reflective Design in proceedings of Critical Computing Aarhus Denmark 